Wegen Gleichheit der linken Seite ist:

Setzen wir

$$
\begin{aligned}
& \frac{\sin \alpha}{\sin \left(180-\alpha-x_{1}\right)}=\frac{\sin \beta}{\sin \left(180-\beta-x_{1}-\Delta\right)} \\
& \text { I } 80-\alpha=a \quad \text { г } 80-\beta-\Delta=b
\end{aligned}
$$

so erhalten wir:

$$
\sin \alpha \sin \left(b-x_{1}\right)=\sin \beta \sin \left(a-x_{1}\right) \text {. }
$$

Wenn man die Multiplikation durchführt und dann durch $\sin \alpha$ dividiert, ergibt sich:

$$
\left(\sin b-\frac{\sin \beta}{\sin \alpha} \sin a\right) \cos x_{1}=\left(\cos b-\frac{\sin \beta}{\sin \alpha} \cos a\right) \sin x_{1}
$$

oder

$$
\operatorname{ctg} x_{1}=\frac{\cos b-\frac{\sin \beta}{\sin \alpha} \cos \alpha}{\sin b-\frac{\sin \beta}{\sin \alpha} \sin a}
$$

Wird dieser Wert von $x_{1}$ in (2) eingesetzt (log $r$ nach Dr. Graff $=3.2405492$ ), erhalten wir die absolute Höhe des Gebildes.

Bei der praktischen Berechnung ist es zweckmäßig, als erste Beobachtung die zu nehmen, welche nach Formel (I) das kleinste $K+x$ gibt. Die weiteren Beobachtungen sind am geeignetsten nach steigendem $K+x$ zu ordnen, so daß

Nyitra, Ungarn, 1906 Mai 27. als letzte Beobachtung die gelte, die den gröBten Wert von $K+x$ gibt.

Es erübrigt noch die Berechnung der Zenitdistanz, also der Größen I $80-\alpha$, I $80-\beta \ldots$, welche erhalten werden durch die Formel

$$
\frac{\sin (K+x)}{\sin h}
$$

oder, wenn wir für $\sin h$ den numerischen Wert einsetzen:

$$
\begin{aligned}
& \sin \alpha=7.6554084 \sin \left(K^{\prime}+x_{1}\right) \\
& \sin \beta=7.6554084 \sin \left(K^{\prime \prime}+x_{2}\right) .
\end{aligned}
$$

Gyula Schöndorfer.

\title{
Observations of Phoebe in May and June 1906.
}

\section{(Harvard College Observatory Circular No. II8).}

Six photographs of Saturn, showing images of Phoebe, have been obtained with the 24 -inch Bruce Telescope at Arequipa. They are given in Table $I$ in a form which is nearly the same as that contained in Circular 109 (A. N. I 71.23), for the similar observations of I905. The designation of the plate, the date, the Greenwich Mean Time of the middle of the exposure, and the duration of the exposure are given in the first four columns. The difference in right ascension, the difference in declination, the distance, and the position angle are given in the fifth, sixth, seventh, and eighth columns. Of these, the sixth and seventh are the measured quantities, the fifth and eighth are derived from them by computation. Computed values for the differences in right ascension and declination were taken from the

\begin{tabular}{|c|c|c|c|c|c|c|c|c|c|c|}
\hline Plate & 1906 & & G. M. T & Exp. & $\begin{array}{l}\text { Difference } \\
\text { in R. A. }\end{array}$ & $\begin{array}{l}\text { Difference } \\
\text { in Decl. }\end{array}$ & $\begin{array}{c}\text { Di- } \\
\text { stance }\end{array}$ & P. A. & $\begin{array}{l}\mathrm{O}-\mathrm{C} \\
\text { R. A. }\end{array}$ & $\begin{array}{l}O-C \\
\text { Decl. }\end{array}$ \\
\hline A 7674 & May I & 18 & $2 I^{h} 3$ & I $20^{m}$ & $-1^{\mathrm{m}} 34^{\mathrm{s}} \mathrm{I}$ & - $10: 8$ & $25: 7$ & $245^{\circ} \circ$ & $-0^{3} \cdot 5$ & $-0: 2$ \\
\hline A 7676 & $\geqslant I$ & I9 & 217 & I 20 & -1 33.8 & $-\mathrm{x} \times .0$ & 25.7 & 244.7 & -0.1 & -0.4 \\
\hline A 7745 & June & 25 & & 120 & -126.8 & -9.0 & $23 \cdot 3$ & $247 \cdot 3$ & --1.0 & +0.1 \\
\hline A 7754 & $\geqslant$ & 26 & I 855 & 120 & -126.3 & -9.0 & 23.2 & 247.2 & -1.0 & 0.0 \\
\hline A $775^{8}$ & 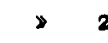 & 27 & r 859 & 120 & -125.4 & -9.0 & 23.0 & 247.1 & -0.7 & 0.0 \\
\hline A 7763 & $\gg$ & 28 & I 8 & I 2 I & -125.0 & -9.0 & 22.9 & 246.9 & -0.8 & -0.1 \\
\hline
\end{tabular}
ephemeris given on the leaf following the Contents in the second edition of the American Ephemeris and Nautical Almanac for 1906 , and subtracted from the observed values in the fifth and sixth columns. The residuals are given in the ninth and tenth columns. The measures were made by Mr. E. S. Manson, Jr.

Table I. Positions of Phoebe rgo6.

If desired, more precise measures of these photographs can be made. As the uncertainty in each coordinate rarely exceeds $0: 1=6 "$, it does not seem as if this would be necessary, at least until elements are determined which will represent the earlier positions more closely.

Harvard College Observatory, Cambridge, Mass., 1906 Aug. I 9. 